\title{
Ultrasensitive detection of cadmium ions using a microcantilever-based piezoresistive sensor for groundwater
}

\author{
Dinesh Rotake ${ }^{* 1}$, Anand Darji1 and Nitin Kale ${ }^{2}$
}

Open Access

\author{
Full Research Paper \\ Address: \\ ${ }^{1}$ Department of Electronics Engineering, Sardar Vallabhbhai National \\ Institute of Technology, Surat, Gujarat, India and ${ }^{2}$ The Chief \\ Technology Officer, NanoSniff Technologies Pvt. Ltd., F-14, 1st Floor, \\ IITB Research Park, Old CSE Building, IIT Bombay, Powai, Mumbai - \\ 76 , India. \\ Email: \\ Dinesh Rotake* - dinesh.rotake@gmail.com \\ * Corresponding author \\ Keywords: \\ BioMEMS; heavy metal ions (HMIs); limit of detection (LOD); \\ microcantilevers; microfluidics; micro-electromechanical systems \\ (MEMS); piezoresistive sensors; SAM (self-assembled monolayers); \\ World Health Organization (WHO)
}

Beilstein J. Nanotechnol. 2020, 11, 1242-1253.

doi:10.3762/bjnano.11.108

Received: 04 April 2020

Accepted: 29 July 2020

Published: 18 August 2020

This article is part of the thematic issue "Functional nanostructures for electronics, spintronics and sensors".

Guest Editor: A. S. Sidorenko

(C) 2020 Rotake et al.; licensee Beilstein-Institut. License and terms: see end of document.

\begin{abstract}
This paper proposes the selective and ultrasensitive detection of $\mathrm{Cd}(\mathrm{II})$ ions using a cysteamine-functionalized microcantileverbased sensor with cross-linked DL-glyceraldehyde (DL-GC). The detection time for various laboratory-based techniques is generally 12-24 hours. The experiments were performed to create self-assembled monolayers (SAMs) of cysteamine cross-linked with DL-glyceraldehyde on the microcantilever surface to selectively capture the targeted $\mathrm{Cd}(\mathrm{II})$. The proposed portable microfluidic platform is able to achieve the detection in 20-23 min with a limit of detection (LOD) of $0.56 \mathrm{ng}(2.78 \mathrm{pM}$ ), which perfectly describes its excellent performance over other reported techniques. Many researchers used nanoparticle-based sensors for the detection of heavy metal ions, but daily increasing usage and commercialization of nanoparticles are rapidly expanding their deleterious effect on human health and the environment. The proposed technique uses a blend of thin-film and microcantilever (micro-electromechanical systems) technology, which mitigate the disadvantages of the nanoparticle approaches, for the selective detection of Cd(II) with a LOD below the WHO limit of $3 \mu \mathrm{g} / \mathrm{L}$.
\end{abstract}

\section{Introduction}

Water is fundamentally essential for sustaining life, and an increase in the global population has led to an exponential increase in waste disposal, which causes significantly increased requirements regarding the control of water quality [1]. Clean water is one of the main priorities of the 21 st century world- wide, and negligence to this may have a significant effect on maintaining the safety and security of human beings [2,3]. One common water contamination is caused by cadmium ions. There are numerous sources of $\mathrm{Cd}$ ions in groundwater, including industrial wastewater, mining industry, fossil fuels, iron and 
steel industry, cement manufacturing units, electroplating industry, manufacturing units of PVC, Ni-Cd batteries, fertilizers, pesticides, photovoltaic devices, soil, and sediments. Cadmium is a highly toxic heavy metal ion (HMI). Cadmium poisoning may cause fatigue, headaches, nausea, vomiting, abdominal cramps, bone degeneration, diarrhea, osteoporosis, renal dysfunction, cancer, anemia, and neurological disorders such as Parkinson's disease or Alzheimer's disease [4,5]. The WHO has set a water contamination limit of $3 \mu \mathrm{g} / \mathrm{L} \mathrm{Cd}$ (II) [6]. We conclude from the WHO limit that cadmium is hazardous, and smaller $\mathrm{Cd}$ concentrations below the limit is also hazardous. Hence, it is essential to sense $\mathrm{Cd}(\mathrm{II})$ in the picomolar (pM) range well below the specified WHO limit.

The ion-selective electrodes (ISEs) fabricated by [7] are stable and precise for HMI detection, but the measurement requires by laboratory equipment. Sensors based on nanotubes, nanorods, nanoneedles, or nanoplates are also used to detect HMIs selectively down to the nanomolar range [8-11]. Many authors used adsorption methods to extract heavy metal ions from groundwater [12-16]. However, this is only useful when a pollution source has been already identified. Sensors based on luminescence or fluorescence sensors have been used by many researchers to selectively detect HMIs [17-22]. However, this method also requires laboratory equipment for analysis and detection. Also, most of the reported fluorescent probes reply only on absorption and fluorescence change and need dynamic acquisition [23]. A magnetic field powered pressure sensor proposed by Khan et al. [24] is capable of measuring pressure in the range of kilopascals but the suitability for the very low pressure caused by HMIs needs to be examined. A reduced graphene oxide (RGO)-based sensor and a microfluidic platform fabricated by [25-27] can be used with some surface modification for HMIs, but it is mostly capable of detecting in the micromolar range. A polymer-based microcantilever using an encapsulated piezoresistor has been proposed by Kale et al. [28], but it is not suitable for other high-temperature sputtering processes. Microcantilevers based on $\mathrm{SiO}_{2}$ have been manufactured by Tang et al. [29] to enhance the sensitivity of cantilever sensors. Many authors use optical setups for microcantilevers. However, an optical output has several disadvantages during operation in water when the refractive index of water changes [30,31].

Many authors have proposed electrode-based approaches for the selective sensing of Cd(II) [32], but the limits of detection were always in the micromolar to nanomolar ranges. Some of the authors used fluorescent [5,33] and calorimetric [34] approaches to selectively detect the $\mathrm{Cd}(\mathrm{II})$. But these approaches required laboratory equipment for analysis and the LODs were also in the nanomolar range. All these methods are reliable for the qualitative and quantitative determination of $\mathrm{Cd}(\mathrm{II})$, but they are time-consuming, expensive, and not suitable for on-site determination. The calorimetric approach proposed by [34-37] is free from these problems but not capable of differentiating between two nearby ranges and the LOD is also on the higher side. The electrochemical sensor described in [38] is a good approach, but it also requires a lab instrument for measurement.

We have previously investigated SAMs of homocysteine (HCys) and pyridinedicarboxylic acid (PDCA) for the selective sensing of $\mathrm{Hg}$ (II) ions using a portable piezoresistive platform $[39,40]$. Experimental results confirmed that proposed setup is capable of sensing in the picomolar range. In this paper, we have used the previously designed portable piezoresistive platform for the selective capture $\mathrm{Cd}(\mathrm{II})$ in the picomolar range. Preliminary results show that the fabricated device has an excellent response within $20-23$ minutes with $0.56 \mathrm{ng} / \mathrm{mL}(2.78 \mathrm{pM})$ LOD, which is well below the WHO limit for cadmium ions.

The paper describes the methodology, the formation of SAMs and their characterization using field-emission scanning electron microscopy (FESEM), the use of the portable experimental platform with the MEMS-based piezoresistive device to selective capture $\mathrm{Cd}(\mathrm{II})$ at the picomolar level and the verification of the experimental results using energy-dispersive X-ray spectroscopy (EDX).

\section{Fabrication and Calibration of the Piezoresistive Device}

Previously, a polysilicon-based piezoresistive sensor was fabricated using a standard microfabrication process. It was calibrated using atomic force microscopy (AFM) [40]. The process begins with thermal oxidation of $\mathrm{Si}$ at $1000{ }^{\circ} \mathrm{C}$ using an oxidation furnace to obtain a thermally grown $\mathrm{SiO}_{2}$ layer followed by masking and etching to get the desired pattern. The polysilicon is deposited in a low-pressure chemical vapor deposition (LPCVD) furnace at $630{ }^{\circ} \mathrm{C}$ and boron doping $\left(10^{18}\right.$ per $\left.\mathrm{cm}^{3}\right)$ is carried out using ion implantation at $35 \mathrm{keV}$. The upper $\mathrm{SiO}_{2}$ layer is formed by re-oxidizing the polysilicon in an oxidation furnace [40]. The stiffness $(k)$ of the fabricated piezoresistive sensor measured using AFM is $131-146 \mathrm{mN} / \mathrm{m}$, which is well below the stiffness required for BioMEMS applications (1000 $\mathrm{mN} / \mathrm{m}[41,42])$. COMSOL 5.3 software is used to perform design and simulation of the piezoresistive sensor to optimize the dimensions for better stiffness and sensitivity [43]. The fabricated piezoresistive sensor layer structure with thickness, FESEM image, PCB, and the experimental platform is shown in Figure 1.

For using the microcantilever device for selectively detecting $\mathrm{Cd}(\mathrm{II})$ a surface modification is required. The surface modifica- 


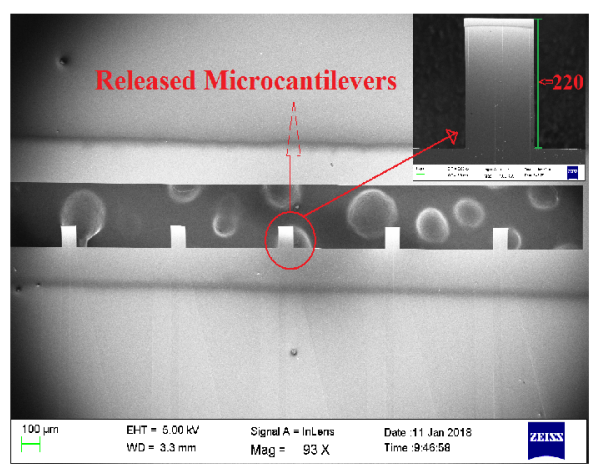

(b) FESEM image of piezosensor

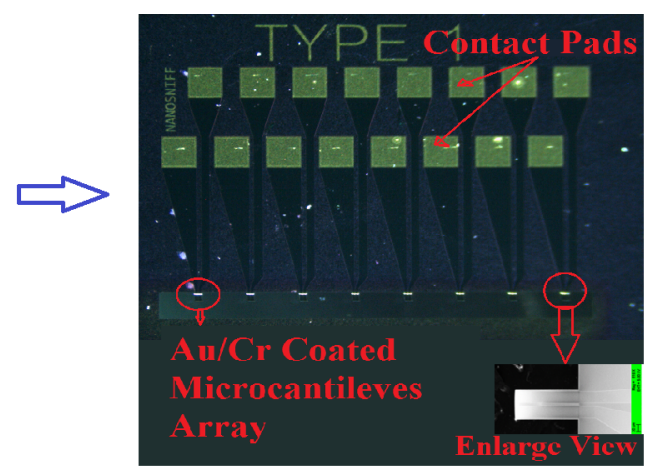

(c) Optical microscope view of PCB

$\sqrt{3}$

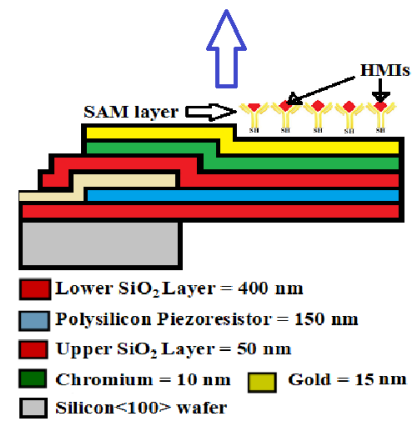

(a) Fabricated piezosensor layer structure \& thickness

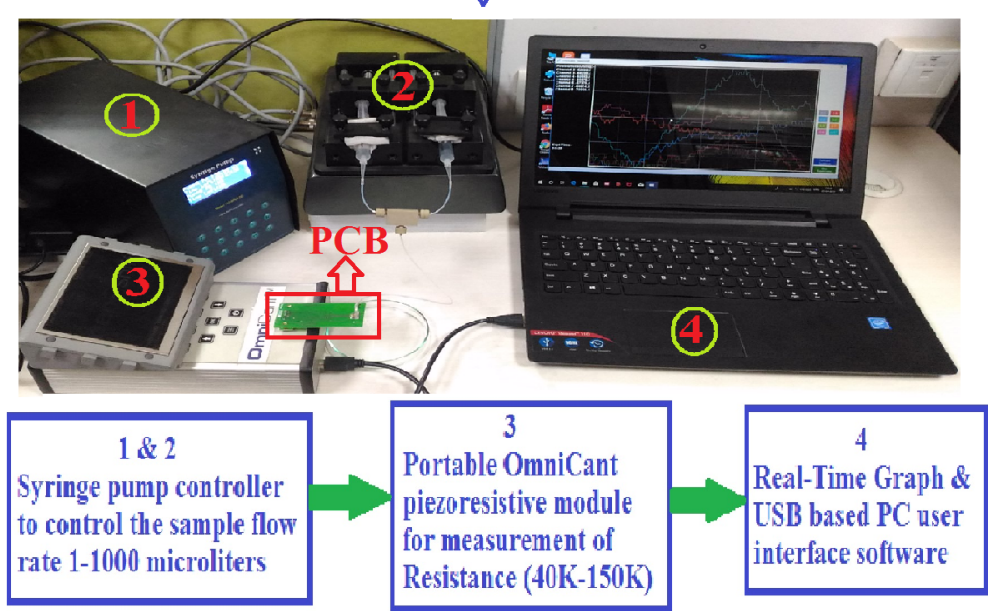

(d) Portable Experimental Setup for Cadmium detection

Figure 1: Fabricated piezoresistive sensor and experimental platform for $\mathrm{Cd}(\mathrm{II})$ detection.

tion of the sensor is basically a selective thiol coating on top of a gold surface. Here, SAMs of cysteamine-glyceraldehyde were created on top of microcantilever-based sensors with integrated piezoresistive readout to get the change in resistance due to changes in surface stress. Until now, many people have used lab-based optical setups to measure the change in surface stress of the cantilever sensors. Moreover, the proposed piezoresistive device has capabilities to directly capture the surface stress make this a better option for HMI applications.

\section{Microfluidic Platform with Piezosensor}

In the proposed method, the benefits of three different technologies are combined, namely thin film, nanoparticles (NPs), and MEMS, to selectively target $\mathrm{Cd}$ (II) in the picomolar range. Also, excessive commercialization of nanoparticles leads to increasing their harmful effect on life and the environment by [44-46]. In this article, an attempt is made to expand the AuNP- based technology proposed by [34] for the ultrasensitive sensing of Cd(II) with cysteamine-functionalized DL-glyceraldehyde (Cys-DL-GC) using the advanced MEMS-based piezoresistive platform. The MEMS-based sensor has very high sensitivity compared to any other technique. The complete process flow and the sensing scheme for the piezoresistive microcantileverbased biosensor is shown in Figure 2.

Here, the fabricated microfluidic platform with a microcantilever-based piezoresistive sensor is used to capture $\mathrm{Cd}(\mathrm{II})$ in the picomolar range. The amine group $\left(-\mathrm{NH}_{2}\right)$ of cysteamine has an affinity to all types of HMIs and it needs to be crosslinked for selectivity. We have cross-linked the amine group with DL-glyceraldehyde at $\mathrm{pH} 7$ to obtain a free - $\mathrm{OH}$ group (a Lewis acid) for capturing $\mathrm{Cd}(\mathrm{II})$. The $\mathrm{pKa}$ value of 12.6 of DL-glyceraldehyde yield a strong copmplex of the $-\mathrm{OH}$ group with cadmium [34] after blocking the $-\mathrm{NH}_{2}$ group of cysteamine. 


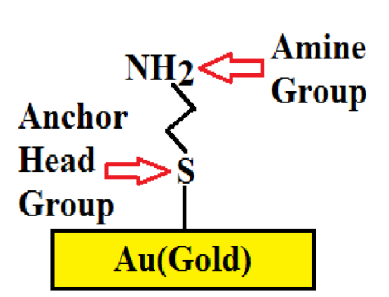

Step-1: SAM formation

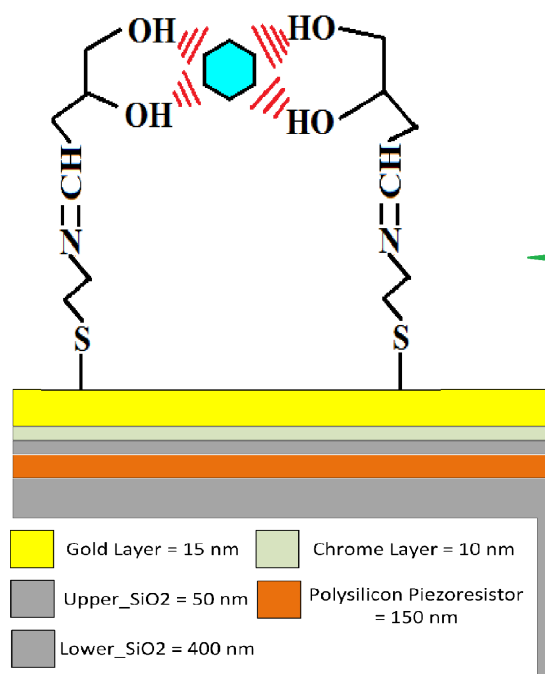

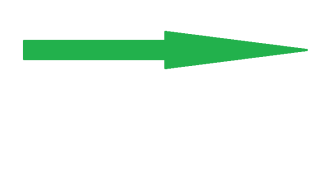

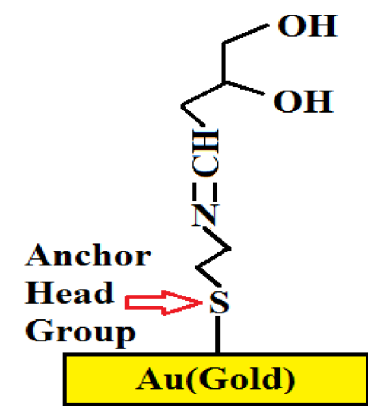

Step-2: Cysteamine cross-linked with DL-glyceraldehyde

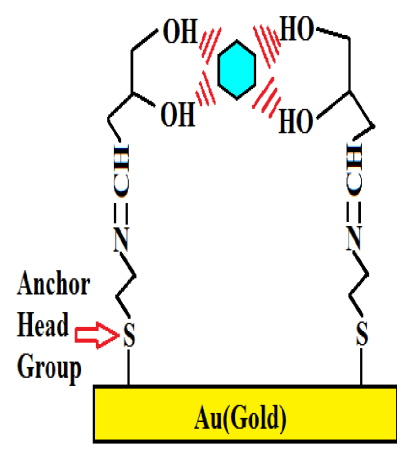

Step-3: Complexing between Au-Cys-DL-GC and Cd2+ Ions

\section{Step-4: Au-Cys-DL-GC-Cd2+ Ions Binding will change the surface stress of Piezosensor causing change in resistance}

Figure 2: Process flow of biosensor for selective detection of $\mathrm{Cd}(\mathrm{II})$ ions.

\section{Results and Discussion}

The performance of the fabricated device in the selective detection of $\mathrm{Cd}(\mathrm{II})$ in a microfluidic environment is evaluated using the OmniCant setup shown in Figure 1d. The non-stress calibrated resistance values of the piezoresistive sensor using SAMs of cysteamine cross-linked with DL-glyceraldehyde (CysDL-GC) is in the range of 56268-63813 $\Omega$. The non-stress resistance values of the fabricated piezoresistive die in the OmniCant microfluidic platform are shown in Figure 3. The microcantilever in channel 2 was blocked with acetyl chloride and selected as a reference for the Cys-DL-GC experiments. The values shows that the microcantilevers in channels 1 and 8 broke during the wire bonding and are not present in the analysis. The piezoresistive MEMS devices exhibit a fast response to changes in the resistance depending on the additional mass of $\mathrm{Cd}(\mathrm{II})$ loaded on the surface.

\section{Results of the SAM detecting cadmium ions}

The proposed microfluidic platform provides real-time monitoring of $\mathrm{Cd}(\mathrm{II})$ in groundwater. We performed the experiment

\section{OmniCant:Liquid Phase Analysis}

\section{Calibrated Values:-}

Channel 2 - 61277.7 ohms

Channel 3 - 62699.9 ohms

Channel 4 - 63813.2 ohms

Channel 5 - 56268.2 ohms

Channel 6 - 57429.0 ohms Channel 7 - 61140.7 ohms

Figure 3: Non-stress calibrated values for used piezoresistive die.

using the coating of cysteamine thiol with cross-linked DL-glyceraldehyde (Cys-DL-GC). We have already discussed that the methods based on $\mathrm{Au} / \mathrm{Ag}$ nanoparticles require the laboratory equipment such as fluorescence spectroscopy, which ultimately leads to a non-portable platform. Hence, our primary focus is the selective detection of the Cd(II) using the fabricated portable experimental platform. 
We used the following experimental procedure. A stock solution of cysteamine ([Cys] $=10 \mathrm{mM} / 10 \mathrm{~mL}$ ) was prepared. The piezoresistive devices were gently dipped into a petri-dish containing cysteamine thiol for at least 12-24 hours. Longer times yield a better packing density of the SAM. In addition, a $2 \%$ $(0.2 \mathrm{~g} / 10 \mathrm{~mL})$ solution of DL-glyceraldehyde (DL-GC) in phosphate buffer saline (PBS, pH 7) according to [34] was prepared. The cysteamine SAM was allowed to cross-link with the DL-glyceraldehyde solution for at least $2-3$ hours by covering the container using silver foil. Stock solutions of $1 \mathrm{mM} / 10 \mathrm{~mL}$ of different salts $\left(\mathrm{AlCl}_{3}, \mathrm{MnCl}_{2}, \mathrm{CrCl}_{3}, \mathrm{HgCl}_{2}, \mathrm{PbCl}_{2}, \mathrm{CdCl}_{2}\right)$ were used for the experiments. The flow rate was kept constant at $30 \mu \mathrm{L} / \mathrm{min}$ during the experiments. Before the measurement, DI water was used to stabilize the microcantilever in a liquid environment for a period of $7 \mathrm{~min}$. Subsequently, the different heavy metal ion solutions were injected separately and the corresponding change in piezoresistance was measured. $\mathrm{The} \mathrm{Cd}(\mathrm{II})$ solution was injected and the corresponding change in piezoresistance was measured.

The change in piezoresistance $(\Delta R)$ is calculated using a formula:

$$
\Delta R=\left[\Delta R_{\text {Block }}-\Delta R_{\text {Unblock }}\right]
$$

where $\Delta R_{\mathrm{Block}}$ is the change in piezoresistance of the microcantilever blocked with acetyl chloride and $\Delta R_{\text {Unblock }}$ is the change in piezoresistance of the unblocked microcantilever. The change in piezoresistance of unblocked microcantilever compared to that of the blocked microcantilever of acetyl chloride (channel 2) is shown in Figure 4.

Initially, we used DI water to stabilize the microcantilever for a period of $7 \mathrm{~min}$. The change of piezoresistance remained constant during this period. When the different heavy metal ion solutions (except $\mathrm{Cd}(\mathrm{II})$ ) were injected after $7 \mathrm{~min}$, the change in piezoresistance was minimal (5-30 $\Omega$ ). When cadmium ions were injected after $7 \mathrm{~min}$, the change in piezoresistance was around 200-300 $\Omega$ for each microcantilever. These results show the selectivity of the proposed method for $\mathrm{Cd}(\mathrm{II})$ with respect to other HMIs. It is also evident that the microcantilever in channel 5 (Figure 4c) shows a non-linear response. The rationale behind this is that no binding sites are available for cadmium ions on the microcantilever surface. Two microcantilevers exhibit a decrease in resistance because of tensile stress due to a small number of biomolecules (Cd(II)) binding to the surface (Figure 4b,d), while the other three microcantilevers exhibit an increase in the resistance because of compressive surface stress when a large number of biomolecules bind to the microcantilever surface (Figure 4a,c,e) [47].
Figure 5 demonstrates the average change in piezoresistance of a sensor based on Au-Cys-DL-GC-coated cantilevers for different heavy metals $\left(\mathrm{AlCl}_{3}, \mathrm{MnCl}_{2}, \mathrm{CrCl}_{3}, \mathrm{HgCl}_{2}, \mathrm{PbCl}_{2}\right.$, $\mathrm{CdCl}_{2}$ ).

The average value of change in piezoresistance is the difference between the average change in piezoresistance for DI water and the particular heavy metal injected. Our results show that the SAM of cysteamine with cross-linked DL-glyceraldehyde(Cys-DL-GC) has a higher selectivity for Cd(II) than for other heavy metals. The average value of change in piezoresistance of the Au-Cys-DL-GC-coated microcantilevers is approximately 130-240 $\Omega$ for $\mathrm{Cd}(\mathrm{II})$ and 5-30 $\Omega$ for the other injected heavy metals. The total value of the average change in piezoresistance for a concentration of $0.56 \mathrm{ng} \mathrm{Cd}(\mathrm{II})$ is $877.72 \Omega$.

\section{Characterization using Fourier-transform infrared spectroscopy (FTIR)}

FTIR is a mature technique for elemental analysis and the identification of functional groups. The FTIR results show $-\mathrm{OH}$ stretching in the range of $2900-3750 \mathrm{~cm}^{-1}$ and $\mathrm{N}-\mathrm{H}$ bending $\left(1350-1750 \mathrm{~cm}^{-1}\right)$ [48-51]. The FTIR analysis of a Cd(II)/DL$\mathrm{GC} / \mathrm{Cys} / \mathrm{Au} / \mathrm{Cr}$ coating is shown in Figure 6.

The FTIR results of the $\mathrm{Cys} / \mathrm{Au} / \mathrm{Cr}$ coating show a single band at $3367 \mathrm{~cm}^{-1}$ associated to the $-\mathrm{OH}$ group and three bands at 1420,1651 , and $1732 \mathrm{~cm}^{-1}$ associated to the $-\mathrm{NH}_{2}$ group. After coating with DL-glyceraldehyde (DL-GC/Cys/Au/Cr), the FTIR spectra show four bands at 1320,1473, 1571, and $1647 \mathrm{~cm}^{-1}$ associated to the $-\mathrm{NH}_{2}$ group and two bands at 2922 and $3311 \mathrm{~cm}^{-1}$ associated to the $-\mathrm{OH}$ group. After exposure to $\mathrm{Cd}(\mathrm{II})$ two bands related to -OH disappear and only single band at $3500 \mathrm{~cm}^{-1}$ is present due $\mathrm{Cd}$ (II) binding to the $-\mathrm{OH}$ groups. Similarly, for $-\mathrm{NH}_{2}$ group), three bands disappear, and only single modified band is present at $1583 \mathrm{~cm}^{-1}$ due $\mathrm{Cd}(\mathrm{II})$ binding. This modification of the FTIR spectra after exposure to $\mathrm{Cd}(\mathrm{II})$ indicates the selective binding of cysteamine crosslinked DL-glyceraldehyde (Cys-DL-GC) to cadmium.

\section{Verification of performed experiment results using EDX}

In general, the thiol groups can bind to all types of HMIs. Thus, to selectively bind and detect $\mathrm{Cd}(\mathrm{II})$ the thiols goups need to be modified or functionalized with materials that are selective for Cd(II). The experimental results show that the fabricated MEMS-based sensor is capable of selective Cd(II) detection using SAMs of cysteamine with cross-linked DL-glyceraldehyde (Cys-DL-GC). To characterize the SAM on the microcantilever device only a few analytical techniques are available because of the fragile nature of the cantilever. FESEM/EDX is the preeminent tool to characterize the SAM on the top of the 

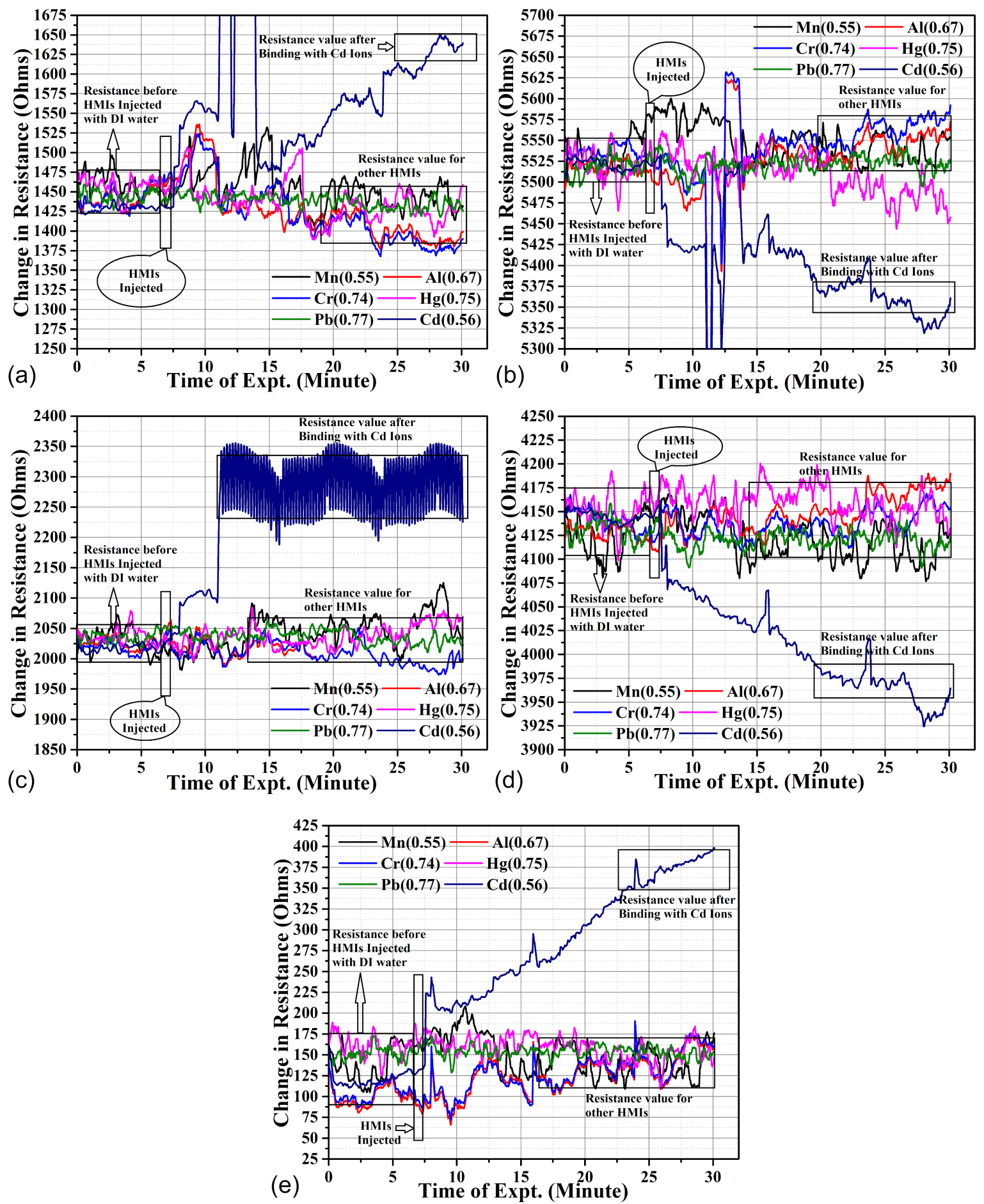

Figure 4: The change in piezoresistance of the unblocked cantilevers with respect to the cantilever blocked with acetyl chloride(channel 2): (a) CysDL-GC (channel 3), (b) Cys-DL-GC (channel 4), (c) Cys-DL-GC (channel 5), (d) Cys-DL-GC (channel 6) and (e) Cys-DL-GC (channel 7).

cantilever without damaging the device. The EDX measurement of the sensor with a SAM of cysteamine cross-linked DL-glyceraldehyde (Cys-DL-GC) on top of a Au surface is shown in Figure 7.
The EDX measurement shows that no cadmium ions are detected before exposure to $\mathrm{CdCl}_{2}$. The EDX measurement of the microcantilever-based MEMS sensor with SAM of cysteamine cross-linked DL-glyceraldehyde (Cys-DL-GC) on 


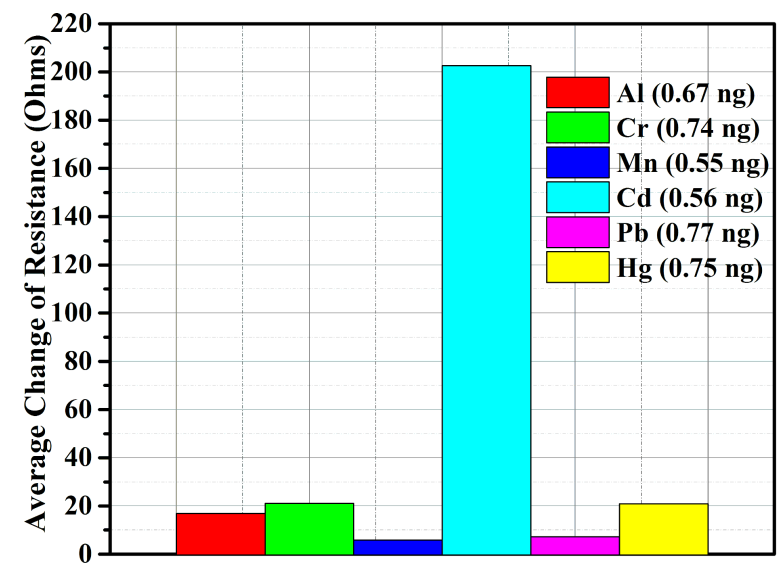

(a)

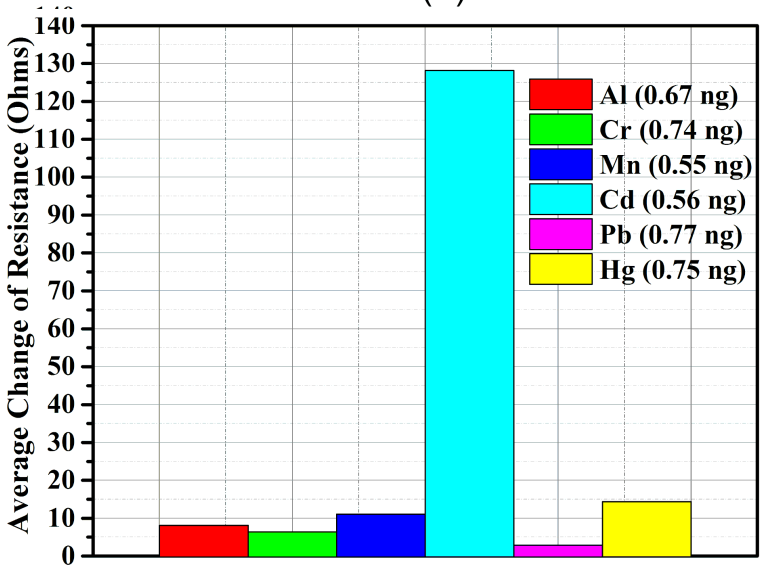

(c)

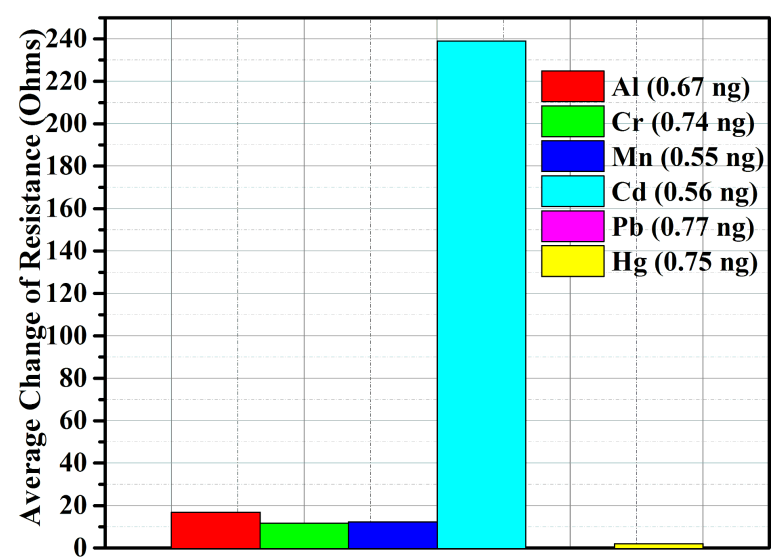

(b)

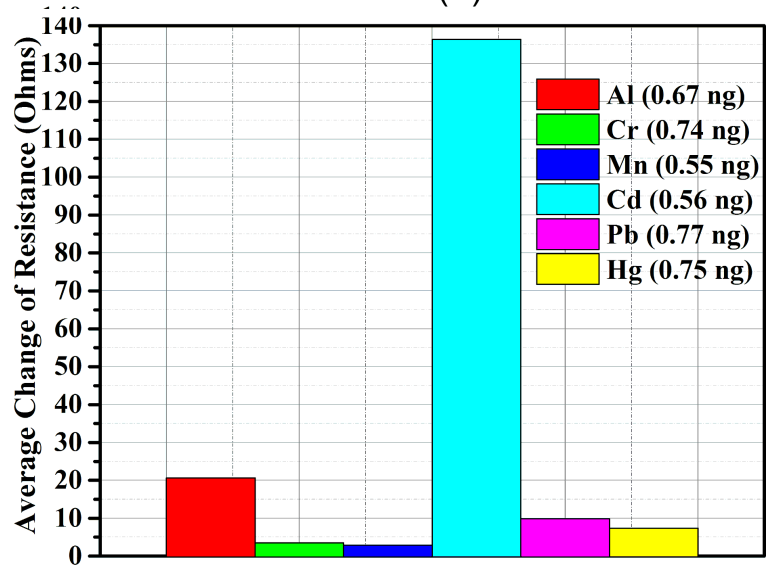

(d)

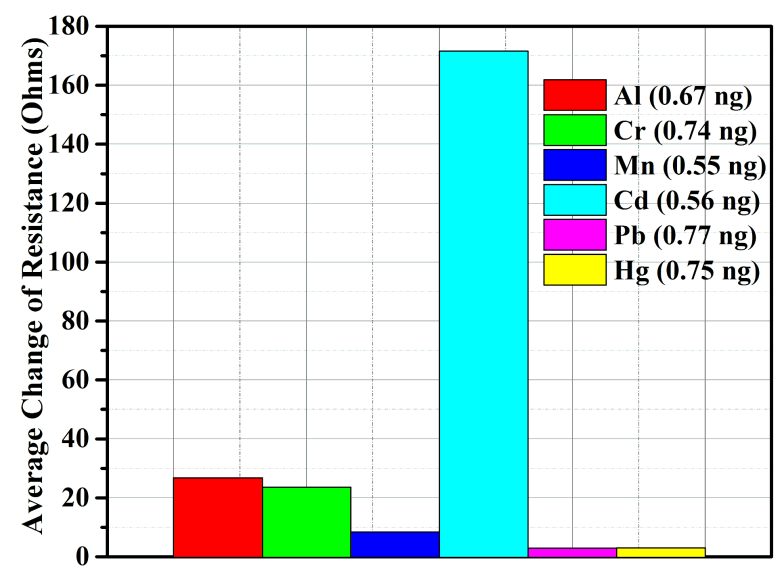

(e)

Figure 5: The average change in piezoresistance of microcantilevers: a) Au-Cys-DL-GC(3), b) Au-Cys-DL-GC(4), c) Au-Cys-DL-GC(5), d) Au-CysDL-GC(6) and e) Au-Cys-DL-GC(7).

top of a $\mathrm{Au}$ surface after exposure to $\mathrm{CdCl}_{2}$ is shown in Figure 8 . The table with the mass percentages (Figure $8 \mathrm{~b}$ ) explicitly shows the presence of $\mathrm{Cd}(\mathrm{II})$, and the percentage number of molecules captured in that scan region.
Table 1 presents a comparative analysis of different techniques to selectively capture $\mathrm{Cd}(\mathrm{II})$ in the picomolar range. We found that the fabricated piezoresistive sensor needs 20-23 min for selectively capturing $\mathrm{Cd}(\mathrm{II})$. At a flow of $30 \mu \mathrm{L} / \mathrm{min}$, the total 


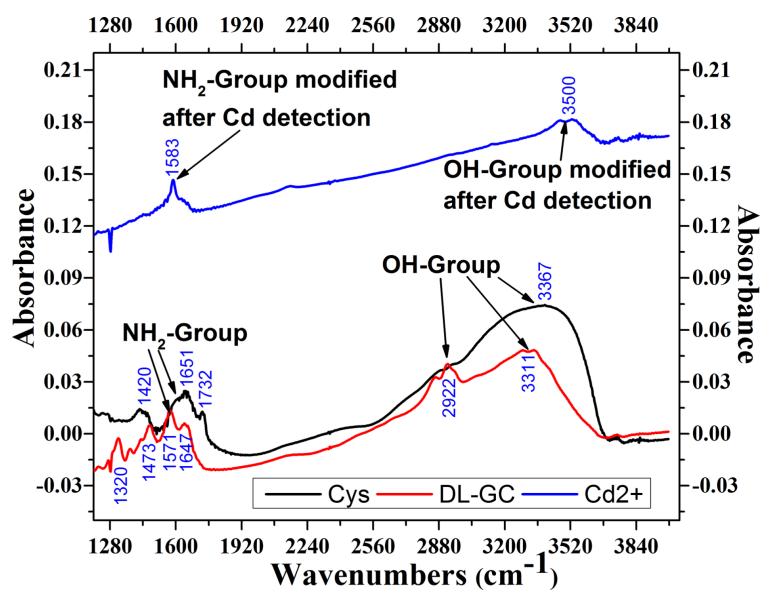

Figure 6: FTIR absorbance spectra of a Cd(II)/DL-GC/Cys/Au/Ti coating. injected volume is $0.69 \mathrm{~mL}$ for a maximum of $23 \mathrm{~min}$. Therefore, the corresponding mass of $\mathrm{AlCl}_{3}, \mathrm{MnCl}_{2}, \mathrm{CrCl}_{3}$, $\mathrm{CdCl}_{2}, \mathrm{PbCl}_{2}$, and $\mathrm{HgCl}_{2}$ is $0.67 \mathrm{ng}, 0.55 \mathrm{ng}, 0.74 \mathrm{ng}, 0.56 \mathrm{ng}$, $0.77 \mathrm{ng}$, and $0.75 \mathrm{ng}$, respectively (refer to [40,52] for LOD calculation)

From the comparison in Table 1, it is clear that the proposed microfluidic platform has the ability to selectively capture $\mathrm{Cd}(\mathrm{II})$ at amounts as small as $2.78 \mathrm{pM} / \mathrm{mL}$ (LOD) and outperforms other approaches, which require sophisticated measuring instruments. The methods proposed by $[4,62,63,65]$ have outstanding potential for a picomolar range of detection but require costly, sophisticated analytical tools $[62,63,65]$. The method proposed by [66] has excellent detection in the picomolar range but authors have not studied the sensor response with respect to time, necessary for real-time sensing. Many authors have used colorimetric or fluorescence techniques for selective HMI
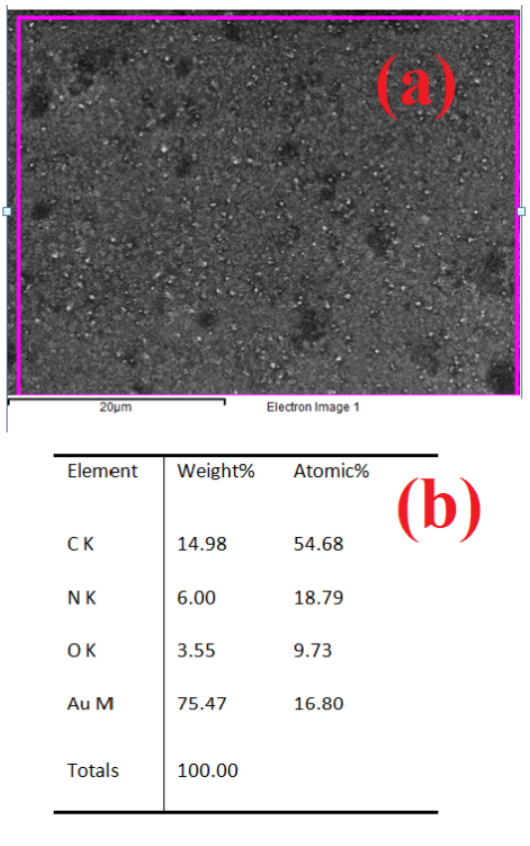

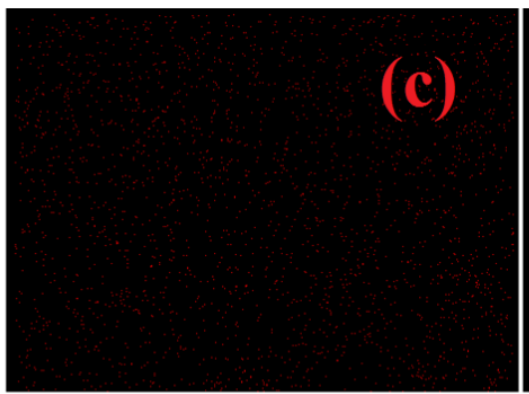

C Ka1_2

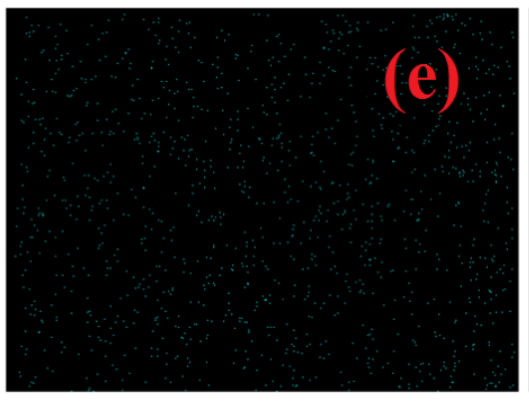

$\mathrm{OKa1}$

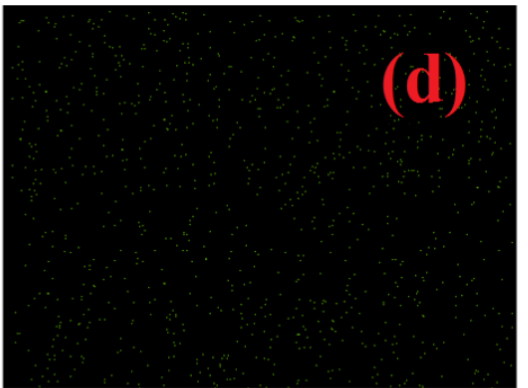

N Ka1_2

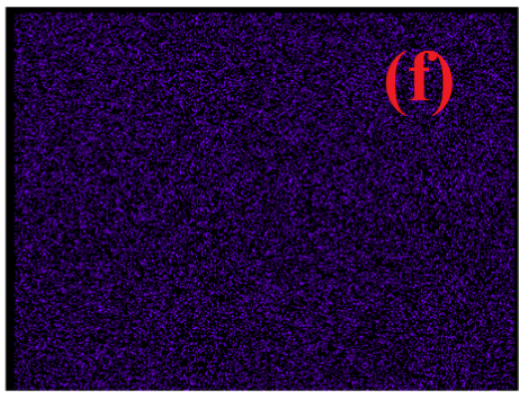

Au Ma1

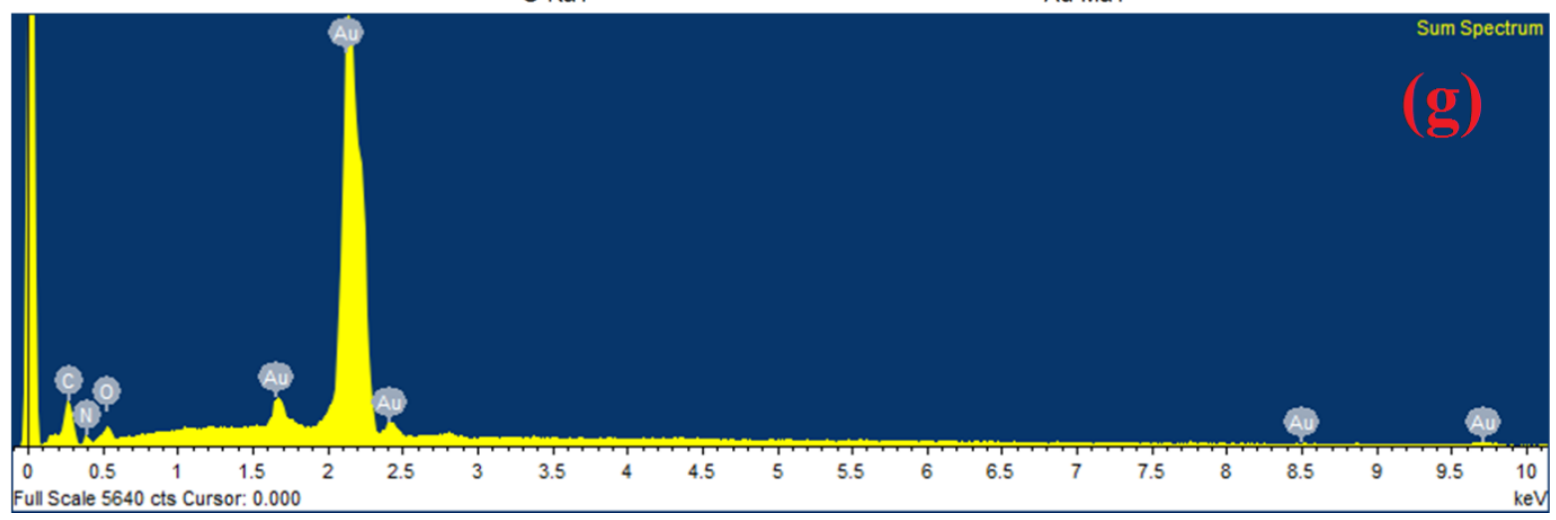

Figure 7: EDX measurement of a SAM of cysteamine (Cys)-cross-linked DL-glyceraldehyde (Cys-DL-GC). (a) Scan area for analysis, (b) table with detected elements, (c-f) color mappings of detected elements, (g) EDX spectrum. 

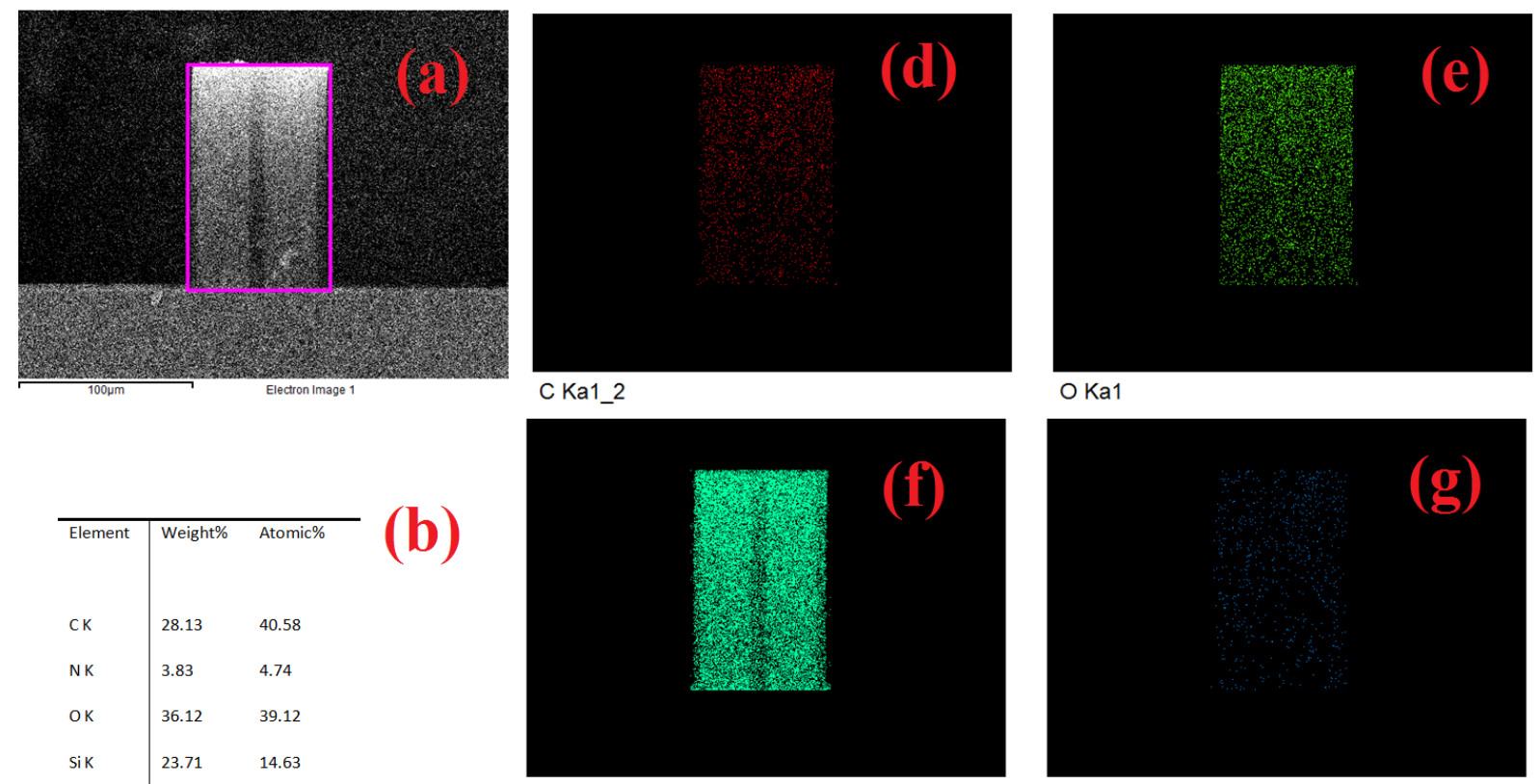

\begin{tabular}{l|ll}
\hline Element & Weight\% & Atomic\% \\
& & \\
CK & 28.13 & 40.58 \\
N K & 3.83 & 4.74 \\
OK & 36.12 & 39.12 \\
Si K & 23.71 & 14.63 \\
ClK & 0.43 & 0.21 \\
\hline Cd L & 0.64 & 0.10 \\
\hline Au M & 7.21 & 0.63 \\
Po M & -0.05 & 0.00 \\
\hline Totals & 100.00 & \\
\hline
\end{tabular}
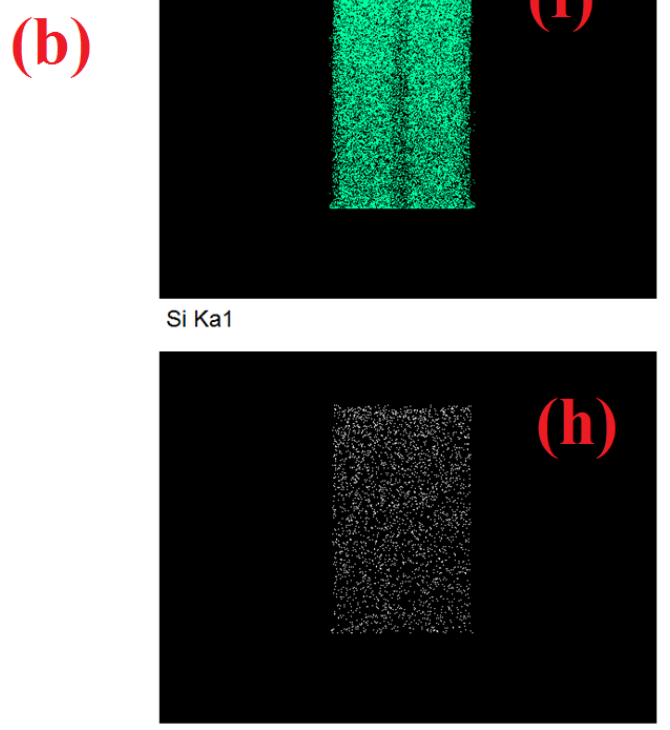

Au Ma1

\section{$\mathrm{Cl} \mathrm{Ka} 1$}
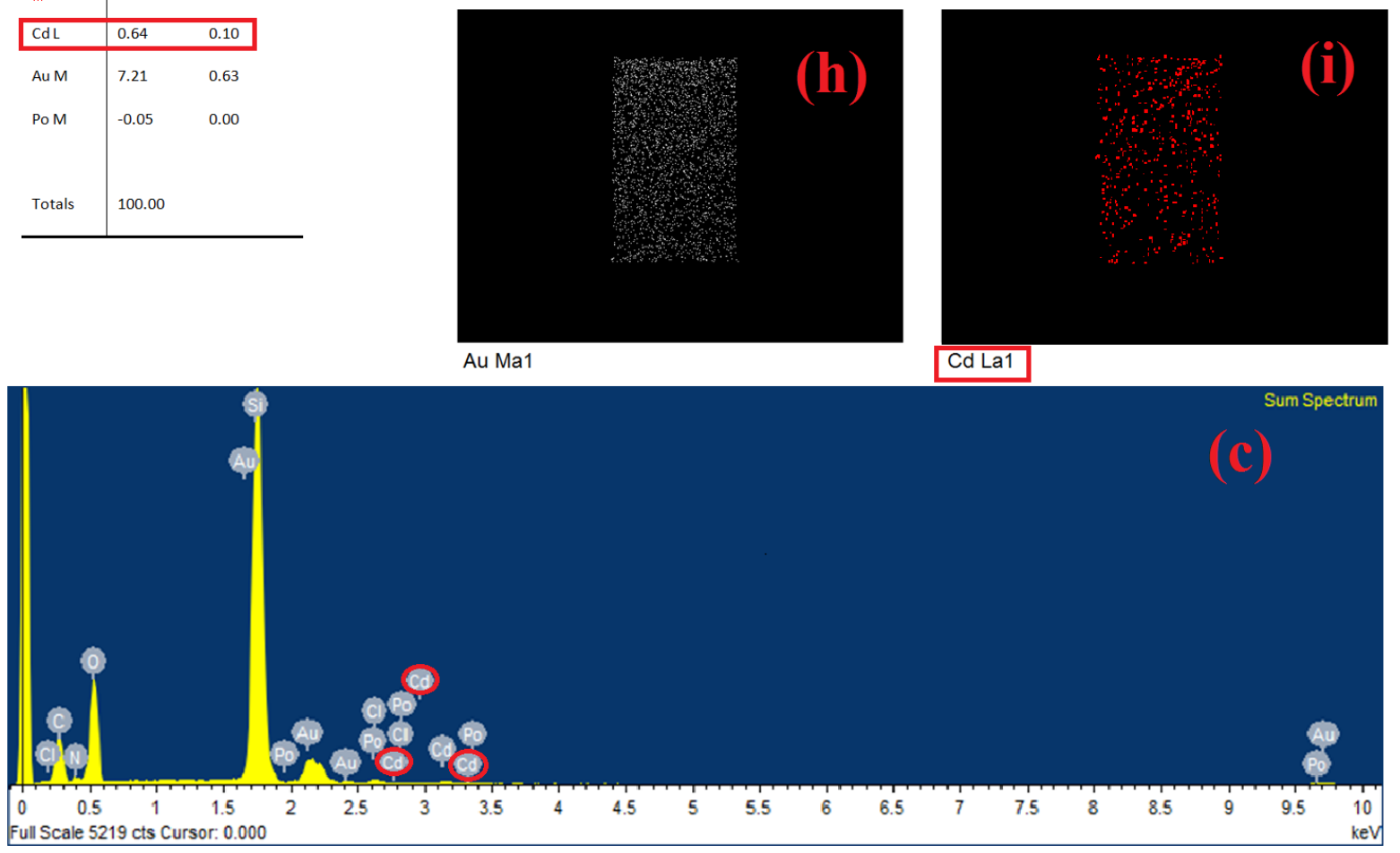

Figure 8: EDX measurement of a SAM of cysteamine (Cys)-cross-linked DL-glyceraldehyde (Cys-DL-GC) after exposure to Cd(II). (a) Scan area for analysis, (b) table with detected elements, (c) EDX spectrum, and (d-i) color mappings of detected elements.

detection but they are highly sensitive to variation of $\mathrm{pH}$ values [67]. In a colorimetric sensor, the concentration variation is shown by different shades of color and it is challenging to exactly identify the shades for the different ranges of concentrations. Both the colorimetric and the fluorescence techniques use NPs and lead to an excessive commercialization of nanoparti- cles, quickly expanding their harmful effect on life and environment, as discussed earlier.

\section{Conclusion}

The proposed microcantilever-based device was tested in a microfluidic setup for the selective detection of cadmium and 


\begin{tabular}{|c|c|c|c|c|}
\hline reference & Analyte (HMI) & $\begin{array}{l}\text { Limit of detection } \\
\text { (LOD) }\end{array}$ & Method used & Detection technique \\
\hline [4] & $\mathrm{Cd}(\mathrm{II})$ & $100 \mathrm{pM}$ & microstructured/optical fiber & fluorescence/absorption spectra \\
\hline [5] & $\mathrm{Cd}(\mathrm{II})$ & $0.5 \mathrm{nM}$ & ratiometric fluorescence & UV-vis spectroscopy/fluorescence spectra \\
\hline [32] & $\mathrm{Cd}(\mathrm{II})$ & $1 \mu \mathrm{M}$ & carbon paste electrode & XRF/XRD/anodic stripping voltammetry \\
\hline [33] & $\mathrm{Cd}(\mathrm{II})$ & $2.15 \mathrm{nM}$ & fluorescent aptamer probe & F-4500/UV-2450 spectrophotometer \\
\hline [34] & $\mathrm{Cd}(\mathrm{II})$ & $21 \mathrm{nM}$ & AuNP based probes & colorimetric/FT-IR/DLS \\
\hline [35] & $\mathrm{Cd}(\mathrm{II})$ & $10 \mu \mathrm{M}$ & AuNP based electrode & colorimetric/UV-vis spectroscopy \\
\hline [38] & $\mathrm{Cd}(\mathrm{II})$ & $1.33 \mathrm{nM}$ & polymeric-NPs/sol-gel & anodic stripping voltammetry (ASV)/FTIR \\
\hline [53] & $\mathrm{Cd}(\mathrm{II})$ & $800 \mu \mathrm{M}$ & LSPR technique & optical fiber setup \\
\hline [54] & $\mathrm{Cd}(\mathrm{II})$ & $2.26 \mathrm{nM}$ & AIGaN/GaN HEMT & high electron mobility transistor (HEMT) \\
\hline [55] & $\mathrm{Cd}(\mathrm{II})$ & $65 \mu \mathrm{M}$ & gold nanoclusters/graphene & fluorescent probe/UV-vis spectroscopy \\
\hline [56] & $\mathrm{Cd}(\mathrm{II})$ & $1 \mu \mathrm{M}$ & gold bioluminescent & fluorescent/microalgae-based \\
\hline [57] & $\mathrm{Cd}(\mathrm{II})$ & $1.062 \mu \mathrm{M}$ & FRET probe-ZnS QD & FTIR/UV-vis/DLS/TEM/(Lab based) \\
\hline [58] & $\mathrm{Cd}(\mathrm{II})$ & $5.56 \mathrm{nM}$ & AuNPs-based & colorimetric system/UV-vis spectra/TEM \\
\hline [59] & $\mathrm{Cd}(\mathrm{II})$ & $18.5 \mu \mathrm{M}$ & fluorometric chemosensor & colorimetric/UV-vis/fluorescent spectra \\
\hline [60] & $\mathrm{Cd}(\mathrm{II}), \mathrm{Pb}(\mathrm{II})$ & $2.23 \mathrm{nM}$ & carbon stencil printed electrode & Raman scattering \\
\hline [61] & $\mathrm{Cd}(\mathrm{II})$ & $4.95 \mu \mathrm{M}$ & silver nanoparticles (AgNPs) & UV-vis/FTIR/TEM \\
\hline [62] & $\mathrm{Cd}(\mathrm{II}), \mathrm{Hg}(\mathrm{II})$ & $10-100 \mathrm{pM}$ & electrochemical sensors & PGSTAT potentiostat \\
\hline [63] & $\mathrm{Cd}(\mathrm{II}), \mathrm{Pb}(\mathrm{II})$ & $49.67 \mathrm{pM}$ & cantilever nanobiosensor & atomic force microscope (AFM) setup \\
\hline [64] & $\mathrm{Cd}(\mathrm{II})$ & $1 \mathrm{nM}$ & $\begin{array}{l}\text { antibody-modified } \\
\text { microcantilever }\end{array}$ & atomic force microscope (AFM) setup \\
\hline [65] & $\mathrm{Pb}(\mathrm{II}), \mathrm{Cd}(\mathrm{II})$ & $1.72-1.58 \mathrm{pM}$ & electrochemical sensor & stripping voltammetry (SWASV) \\
\hline$[66]$ & $\mathrm{Cd}(\mathrm{II})$ & $0.3 \mathrm{pM}$ & electrochemical biosensor & AUTOLAB PGSTAT 30 \\
\hline this work & $\mathrm{Cd}(\mathrm{II})$ & $2.78 \mathrm{pM}$ & piezoresistive sensor & portable setup (real-time analysis) \\
\hline
\end{tabular}

was found to achieve sensing in $20-23 \mathrm{~min}$. The $0.56 \mathrm{ng} / \mathrm{mL}$ $(2.78 \mathrm{pM})$ limit of detection is possible with a SAM of cysteamine cross-linked DL-glyceraldehyde (Cys-DL-GC). The average value of change in piezoresistance of the Au-Cys-DLGC-coated microcantilever is approximately $130-240 \Omega$ for cadmium ions and 5-30 $\Omega$ range for other injected HMIs. The total value of average change in piezoresistance for the concentration of $0.56 \mathrm{ng} / \mathrm{mL}$ for $\mathrm{Cd}(\mathrm{II})$ is $877.72 \Omega$. The most significant feature of this approach is the need for a sample volume of one milliliter. It is also evident from EDX spectra that no other HMIs except $\mathrm{Cd}$ (II) have been found. This EDX finding shows that the fabricated microcantilever-based piezoresistive sensor does not have cross selectivity. In conclusion, this approach could serve as a portable framework for on-site, ultrasensitive, and selective $\mathrm{Cd}(\mathrm{II})$ detection in the picomolar range.

\section{Funding}

The authors would like to thank Director of Indian Institute of Technology, Bombay for the support of atomic force microscopy under "Indian Nanoelectronics Users Program" and "Visvesvaraya Ph.D. Scheme for Electronics and IT" funded by the MeitY and FESEM support under PUMP, NCPRE funded by the MNRE, Government of India.

\section{ORCID ${ }^{\circledR}$ iDs}

Dinesh Rotake - https://orcid.org/0000-0003-2036-463X

\section{Preprint}

A non-peer-reviewed version of this article has been previously published as a preprint doi:10.3762/bxiv.2020.44.v1

\section{References}

1. Vaseashta, A.; Duca, G.; Culighin, E.; Bogdevici, O.; Khudaverdyan, S.; Sidorenko, A. Smart and Connected Sensors Network for Water Contamination Monitoring and Situational Awareness. Functional Nanostructures and Sensors for CBRN Defence and Environmental Safety and Security; Springer, 2020; pp 293-296.

2. Nastasiuc, L. N.; Bogdevici, O. P.; Overcenco, A. V.; Smîslov, V. V.; lacunin, V. S.; Sidorenko, A. S.; Vaseashta, A. Water contaminants monitoring in Moldova; 2015; p 112.

3. Nastasiuc, L.; Bogdevici, O.; Aureliu, O.; Culighin, E.; Sidorenko, A.; Vaseashta, A. Pol. J. Environ. Stud. 2016, 25, 221-230. doi:10.15244/pjoes/58888

4. Heng, S.; Mak, A. M.; Stubing, D. B.; Monro, T. M.; Abell, A. D. Anal. Chem. (Washington, DC, U. S.) 2014, 86, 3268-3272. doi:10.1021/ac500619z 
5. Qian, J.; Wang, K.; Wang, C.; Ren, C.; Liu, Q.; Hao, N.; Wang, K. Sens. Actuators, B 2017, 241, 1153-1160. doi:10.1016/j.snb.2016.10.020

6. Thompson, T.; Fawell, J.; Kunikane, S.; Jackson, D.; Appleyard, S.; Callan, P.; Bartram, J.; Kingston, P. Chemical safety of drinking-water: Assessing priorities for risk management; World Health Organization, 2007; pp 1-142.

7. Criscuolo, F.; Lobello, L.; Taurino, I.; Demarchi, D.; Carrara, S.; De Micheli, G. Mixed Gold and Platinum Nanostructured Layers for All-Solid-State Ion Sensors. 2018 IEEE SENSORS; IEEE, 2018; pp 1-4.

8. Gutierrez, F. A.; Gonzalez-Dominguez, J. M.; Ansón-Casaos, A.; Hernández-Ferrer, J.; Rubianes, M. D.; Martínez, M. T.; Rivas, G. Sens. Actuators, B 2017, 249, 506-514. doi:10.1016/j.snb.2017.04.026

9. Ramírez, M. L.; Tettamanti, C. S.; Gutierrez, F. A.; Gonzalez-Domínguez, J. M.; Ansón-Casaos, A.; Hernández-Ferrer, J.; Martínez, M. T.; Rivas, G. A.; Rodríguez, M. C. Microchem. J. 2018, 141, 271-278. doi:10.1016/j.microc.2018.05.007

10. Jin, L.; Li, J.; Liu, L.; Wang, Z.; Zhang, X. Appl. Nanosci. 2018, 8, 1189-1196. doi:10.1007/s13204-018-0755-3

11. Krasovska, M.; Gerbreders, V.; Mihailova, l.; Ogurcovs, A.; Sledevskis, E.; Gerbreders, A.; Sarajevs, P. Beilstein J. Nanotechnol. 2018, 9, 2421-2431. doi:10.3762/bjnano.9.227

12. Hemavathy, R. R. V.; Kumar, P. S.; Suganya, S.; Swetha, V.; Varjani, S. J. Bioresour. Technol. 2019, 281, 1-9. doi:10.1016/j.biortech.2019.02.070

13. Christopher, F. C.; Anbalagan, S.; Kumar, P. S.; Pannerselvam, S. R.; Vaidyanathan, V. K. IET Nanobiotechnol. 2017, 11, 433-442. doi:10.1049/iet-nbt.2016.0166

14. Yan, Y.; Li, J.; Kong, F.; Jia, K.; He, S.; Wang, B. Beilstein J. Nanotechnol. 2017, 8, 2680-2688. doi:10.3762/bjnano.8.268

15. Kumar, N.; Fosso-Kankeu, E.; Ray, S. S. ACS Appl. Mater. Interfaces 2019, 11, 19141-19155. doi:10.1021/acsami.9b03853

16. Kumar, N.; Reddy, L.; Parashar, V.; Ngila, J. C. J. Environ. Chem. Eng. 2017, 5, 1718-1731. doi:10.1016/j.jece.2017.03.014

17. Song, Z.; Wang, F.; Qiang, J.; Zhang, Z.; Chen, Y.; Wang, Y.; Zhang, W.; Chen, X. J. Lumin. 2017, 183, 212-216. doi:10.1016/j.jumin.2016.11.052

18. Liu, C.; Xiao, T.; Wang, Y.; Wang, F.; Chen, X. Tetrahedron 2017, 73, 5189-5193. doi:10.1016/j.tet.2017.07.012

19. Ma, Y.; Mei, J.; Bai, J.; Chen, X.; Ren, L. Mater. Res. Express 2018, 5, 055605. doi:10.1088/2053-1591/aac419

20. Rao, A. V. R. K.; Reddy, R. B.; Sengupta, S.; Chelvam, V. Appl. Nanosci. 2018, 8, 1973-1987. doi:10.1007/s13204-018-0875-9

21. Makwana, B. A.; Vyas, D. J.; Bhatt, K. D.; Darji, S.; Jain, V. K. Appl. Nanosci. 2016, 6, 555-566. doi:10.1007/s13204-015-0459-x

22. Basu, T.; Rana, K.; Das, N.; Pal, B. Beilstein J. Nanotechnol. 2017, 8, 762-771. doi:10.3762/bjnano.8.79

23. Li, J.; Ge, J.; Zhang, Z.; Qiang, J.; Wei, T.; Chen, Y.; Li, Z.; Wang, F.; Chen, X. Sens. Actuators, B 2019, 296, 126578. doi:10.1016/j.snb.2019.05.055

24. Khan, M. A.; Alfadhel, A.; Kosel, J.; Bakolka, M. Fabrication and characterization of magnetic composite membrane pressure sensor. 2016 IEEE Sensors Applications Symposium (SAS); 2019; pp 1-5.

25. Salem, M.; Javanmard, M. IEEE Sens. Lett. 2018, 2, 1-4. doi:10.1109/Isens.2018.2839090

26. Javanmard, M.; Davis, R. W. Sens. Actuators, B 2011, 154, $22-27$. doi:10.1016/j.snb.2010.03.067
27. Javanmard, M.; Davis, R. W. IEEE Sens. J. 2012, 12, 2733-2734. doi:10.1109/jsen.2012.2198463

28. Kale, N. S.; Nag, S.; Pinto, R.; Rao, V. R. J. Microelectromech. Syst. 2009, 18, 79-87. doi:10.1109/jmems.2008.2008577

29. Tang, Y.; Fang, J.; Yan, X.; Ji, H.-F. Sens. Actuators, B 2004, 97 , 109-113. doi:10.1016/j.snb.2003.08.003

30. Thaysen, J. Cantilever for bio-chemical sensing integrated in a microliquid handling system. Ph.D. Thesis, Technical University of Denmark, Lyngby, Denmark, 2001.

31. Haiden, C.; Wopelka, T.; Jech, M.; Keplinger, F.; Vellekoop, M. J. IEEE Sens. J. 2016, 16, 1182-1189. doi:10.1109/jsen.2015.2501355

32. Ourari, A.; Tennah, F.; Ruíz-Rosas, R.; Aggoun, D.; Morallón, E. Int. J. Electrochem. Sci. 2018, 13, 1683-1699. doi:10.20964/2018.02.35

33. Zhu, Y.-F.; Wang, Y.-S.; Zhou, B.; Yu, J.-H.; Peng, L.-L.; Huang, Y.-Q.; Li, X.-J.; Chen, S.-H.; Tang, X.; Wang, X.-F. Anal. Bioanal. Chem. 2017, 409, 4951-4958. doi:10.1007/s00216-017-0436-1

34. Yadav, R.; Patel, P. N.; Lad, V. N. Res. Chem. Intermed. 2018, 44, 2305-2317. doi:10.1007/s11164-017-3230-y

35. Chen, N.; Chen, J.; Yang, J.-H.; Bai, L.-Y.; Zhang, Y.-P. J. Nanosci. Nanotechnol. 2016, 16, 840-843. doi:10.1166/jnn.2016.11618

36. Sung, H. K.; Oh, S. Y.; Park, C.; Kim, Y. Langmuir 2013, 29 , 8978-8982. doi:10.1021/la401408f

37. Greis, K.; Bethke, K.; Stückrath, J. B.; Ingber, T. T. K.; Valiyaveettil, S.; Rademann, K. Clean: Soil, Air, Water 2019, 47, 1900179. doi:10.1002/clen.201900179

38. Ghanei-Motlagh, M.; Taher, M. A. Chem. Eng. J. 2017, 327, 135-141. doi:10.1016/j.cej.2017.06.091

39. Rotake, D. R.; Darji, A. D.; Kale, N. S. Microelectron. Int. 2019, 37, 10-28. doi:10.1108/mi-05-2019-0025

40. Rotake, D.; Darji, A.; Kale, N. IET Nanobiotechnol. 2020, 14, 357-368. doi:10.1049/iet-nbt.2019.0277

41. Fritz, J.; Baller, M. K.; Lang, H. P.; Rothuizen, H.; Vettiger, P.; Meyer, E.; Güntherodt, H.-J.; Gerber, C.; Gimzewski, J. K. Science 2000, 288, 316-318. doi:10.1126/science.288.5464.316

42. Mathew, R.; Ravi Sankar, A. Nano-Micro Lett. 2018, 10, 35. doi:10.1007/s40820-018-0189-1

43. Rotake, D.; Darji, A. Stiffness and Sensitivity analysis of Microcantilever Based Piezoresistive Sensor for Bio-MEMS Application. IEEE SENSORS, International Symposium; 2018; pp 1584-1875.

44. Asharani, P. V.; lianwu, Y.; Gong, Z.; Valiyaveettil, S. Nanotoxicology 2011, 5, 43-54. doi:10.3109/17435390.2010.489207

45. Kovochich, M.; Xia, T.; Xu, J.; Yeh, J. I.; Nel, A. E. Principles and procedures to assess nanomaterial toxicity. Environmental nanotechnology: applications and impacts of nanomaterials; McGraw Hill: New York, NY, USA, 2007; pp 205-229.

46. Royce, S. G.; Mukherjee, D.; Cai, T.; Xu, S. S.; Alexander, J. A.; Mi, Z.; Calderon, L.; Mainelis, G.; Lee, K.; Lioy, P. J.; Tetley, T. D.;

Chung, K. F.; Zhang, J.; Georgopoulos, P. G. J. Nanopart. Res. 2014, 16, 2724. doi:10.1007/s11051-014-2724-4

47. Wu, S.; Nan, T.; Xue, C.; Cheng, T.; Liu, H.; Wang, B.; Zhang, Q.; $\mathrm{Wu}, \mathrm{X}$. Biosens. Bioelectron. 2013, 48, 67-74. doi:10.1016/j.bios.2013.03.086

48. Patty, D. J.; Loupatty, G.; Sopalauw, F. AIP Conf. Proc. 2017, 1801, 060005. doi:10.1063/1.4973109

49. Kong, J.; Yu, S. Acta Biochim. Biophys. Sin. 2007, 39, 549-559. doi:10.1111/j.1745-7270.2007.00320.x 
50. Liu, Y.; Wu, Y.; Guo, X.; Wen, Y.; Yang, H. Sens. Actuators, B 2019, 283, 278-283. doi:10.1016/j.snb.2018.12.043

51. Rotake, D. R.; Darji, A.; Singh, J. Sens. Rev. 2020, 40, 485-495. doi:10.1108/sr-12-2019-0313

52. Rotake, D.; Singh, J.; Darji, A.; Kumar, A. IET Nanobiotechnol. 2020, 14, in press. doi:10.1049/iet-nbt.2020.0109

53. Dhara, P.; Kumar, R.; Binetti, L.; Nguyen, H. T.; Alwis, L. S.; Sun, T.; Grattan, K. T. V. IEEE Sens. J. 2019, 19, 8720-8726. doi:10.1109/jsen.2019.2921701

54. Nigam, A.; Bhat, T. N.; Bhati, V. S.; Dolmanan, S. B.; Tripathy, S.; Kumar, M. IEEE Sens. J. 2019, 19, 2863-2870. doi:10.1109/jsen.2019.2891511

55. Ju, C.; Gong, X.; Song, W.; Zhao, Y.; Li, R. Micro Nano Lett. 2018, 13, 804-806. doi:10.1049/mnl.2017.0637

56. Wong, L. S.; Judge, S. K.; Voon, B. W. N.; Tee, L. J.; Tan, K. Y.; Murti, M.; Chai, M. K. IEEE Sens. J. 2018, 18, 2091-2096. doi:10.1109/jsen.2017.2787786

57. Safari, S.; Amiri, A.; Badiei, A. Spectrochim. Acta, Part A 2020, 231, 118062. doi:10.1016/j.saa.2020.118062

58. Gan, Y.; Liang, T.; Hu, Q.; Zhong, L.; Wang, X.; Wan, H.; Wang, P. Talanta 2020, 208, 120231. doi:10.1016/j.talanta.2019.120231

59. Pham, T. C.; Kim, Y. K.; Park, J. B.; Jeon, S.; Ahn, J.; Yim, Y.; Yoon, J.; Lee, S. ChemPhotoChem 2019, 3, 1133-1137. doi:10.1002/cptc.201900165

60. Kava, A. A.; Beardsley, C.; Hofstetter, J.; Henry, C. S. Anal. Chim. Acta 2020, 1103, 58-66. doi:10.1016/j.aca.2019.12.047

61. Jabariyan, S.; Zanjanchi, M. A. Appl. Phys. A: Mater. Sci. Process. 2019, 125, 872. doi:10.1007/s00339-019-3167-7

62. Popescu Mandoc, L.-R.; Moldoveanu, I.; Stefan-van Staden, R.-I.; Ungureanu, E. M. Microsyst. Technol. 2017, 23, 1141-1145. doi:10.1007/s00542-016-3039-4

63. Rigo, A. A.; Cezaro, A. M. D.; Muenchen, D. K.; Martinazzo, J.; Manzoli, A.; Steffens, J.; Steffens, C. J. Environ. Sci. Health, Part B 2020, 55, 239-249. doi:10.1080/03601234.2019.1685318

64. Velanki, S.; Kelly, S.; Thundat, T.; Blake, D. A.; Ji, H.-F. Ultramicroscopy 2007, 107, 1123-1128. doi:10.1016/j.ultramic.2007.01.011

65.Zeinu, K. M.; Hou, H.; Liu, B.; Yuan, X.; Huang, L.; Zhu, X.; Hu, J.; Yang, J.; Liang, S.; Wu, X. J. Mater. Chem. A 2016, 4, 13967-13979. doi:10.1039/c6ta04881a

66. Ebrahimi, M.; Raoof, J. B.; Ojani, R. Int. J. Biol. Macromol. 2018, 108 , 1237-1241. doi:10.1016/j.jjbiomac.2017.11.023

67. Charbgoo, F.; Ramezani, M.; Darroudi, M. Biosens. Bioelectron. 2017, 96, 33-43. doi:10.1016/j.bios.2017.04.037

\section{License and Terms}

This is an Open Access article under the terms of the Creative Commons Attribution License (http://creativecommons.org/licenses/by/4.0). Please note that the reuse, redistribution and reproduction in particular requires that the authors and source are credited.

The license is subject to the Beilstein Journal of Nanotechnology terms and conditions: (https://www.beilstein-journals.org/bjnano)

The definitive version of this article is the electronic one which can be found at:

doi:10.3762/bjnano. 11.108 